\title{
Sağl1k Hizmetleri Meslek Yüksekokulu Öğrencilerinin Simülasyon Uygulamalarının Eğitime Katkısı İle İlgili Görüşleri
}

\author{
Öğr. Gör. Selin DENİZ \\ İstanbul Kemerburgaz Üniversitesi Sağlık Hizmetleri Meslek Yüksekokulu İlk ve Acil Yardım Bölümü
}

\begin{abstract}
Özet
Amaç: Simülasyon uygulamalarının eğitime ve ögrenime katklsı ile ilgili görüşlerini incelemek, düşüncelerini saptamak; eğitime, bilime ve topluma fayda sağlamaktır.

Gereç ve Yöntem: Çalışmada yarı yapılandırılmış altı soruyu içeren odak grup görüş̧me yöntemi kullanılmıştır. Örneklem grubuna lise eğitimini Sağllk Meslek Lisesi hemşirelik bölümünde tamamlamış SHMYO İlk ve Acil Yardım Bölümü 1. ve 2. sinıf önlisansögrrencilerinden 30 gönüllü öğrenci seçilmiş ve her grupta 10 öğrenci olmak üzere toplam 3 odak grup görüşmesi yapılmıştır.

Bulgular: Öğrencilerin çoğunluğu mesleğe başlamadan önce laboratuar verilen beceri geliş̧tirme uygulamalarının faydalı olduğunu ifade etmişlerdir. Öğrenciler beceri geliş̧tirme alanlarında bulunan maketlerin yeni ve mekanik olarak dışarıdan yönlendirme ile kontrol edilebilir modelde olmast ve öğrencilerin uygulama derslerini iki ayrı gruba ayrılarak ögrenme alanında az sayıda ögrencinin uygulamaya dahil olmasının birden fazla uygulama yapma şansın oluşturduğundan faydalı olduğunu belirtmiştir. Öğrenciler maketler üzerinde yapılan vaka çalışmaları sayesinde klinik alana çıkmadan önce kendilerini yeterli hissetmeye yardımcı olduğunu ifade etmiştir. Ancak uygulama ders saatlerinin yetersiz olması nedeniyle az vaka çallşması yaptı̆̆ını düşünmektedirler. Uygulama ders saatlerinin arttırlması gerektiğini önererek, böylece daha yetkin olacaklarını düşündüklerini ifade ettiler.

Sonuçlar: Sağllk ĕgitimi bilişsel, duyuşsal ve psikomotor öğrenme ortamlarını kapsayan bir sistem gerektirdiğinden; mezun olan öğrencilerin bu özellikler açısından tam donanımlı olması sağlanmalıdır. Sahaya çıkmadan önce gerçeğe uygun vakalarla birleşmiş ortamı yansitan bir laboratuarda mesleki becerilerini geliştirebilmektedirler. Simülasyon ĕgitiminin, ögrencinin kliniğe hazırlamada etkili olacă̆l, öğrencinin klinik karar verme ve uygulama becerisini geliştirerek, özgüvenini artiracağ dü̈sünülmektedir. Öğrencilere katkl sağlaması nedeniyle, simülasyon uygulamasının eğitim yöntemi olarak kullanılması ve yayginlaşttrılması önerilmektedir.
\end{abstract}

Anahtar Kelimeler: Simülasyon, Sağllk Hizmetleri Meslek Yüksekokulu ögrencileri, Labaratuar uygulamaları.

\footnotetext{
Abstract

Objective:Theaim of thisstudy is toexaminetheopinions of thesimulationapplications on the education and learning contribution, identification of ideasandeducate, informandgatherbenefits.

MaterialandMethod:The study used a focus group interview method with six semi-structured questionnaires.

Findings:The majority of the students stated that the skill-building practices given in the lab were useful before they started to work. The students stated that the models in the skill development areas are new and mechanically controllable by external guidance and that the inclusion of a smallnumber of learners in thefield of learning by dividing the application courses into two separate groups constitutes a chance for more than one application. Through the case studies on the models, the students said that they helped them to feel well before going out to the clinic area. However, they think that they are carrying out few case studies because the application hours are insufficient. The practice suggests that the lesson hours need to be increased, thus expressing that they think they will be come more competent.

Conclusion:Since health education requires a system that includes cognitive, emotional and psychomotor learning environments so it's should be ensured that graduated students are fully equipped in terms of these characteristics. It is an important training method for the students to reach the goal of increasing the clinical competence in the laboratory environment without applying to the patient. They can develop their professional skills in a laboratory that reflects the unified environment in the right circumstances prior to excavation. Students who do not work in a similarway of thinking in the literature think that the training of the simulations taken before applying to the patient will increase their self confidence. Because of the contribution to the students, it is suggested to use and spread the simulation application as a training method. It is also suggested that more effective training can be provided by increasing the hours of work and case studies in the laboratory. KeyWords:Simulation, Health Services Vocational High School students, Labaratorypracties.
} 


\section{Giriş}

Günümüzde eğitim ortamlarında, öğretim sürecinin her aşamasında farklı öğretim teknolojileri kullanılmaktadır. Eğitimde bilgi ve becerilerin geliştirilmesi için birçok eğitim yöntemi ve stratejisi denenmektedir. Eğitim yöntem ve stratejilerinin önemli bir grubunu, bilgisayar destekli eğitim, simülasyon ve uzaktan eğitim yaklaşımları oluşturmaktadır. Öğrencilerin hasta bakım yönetiminde yeterliliğini geliştirmesi ve yetkinlik kazanması için benimsenen yöntemlerinden biri simülasyondur. (1)

Simülasyon; öğrencinin, gerçek yaşam koşullarını yansıtan bir aktivitede, gerçek bir durumun riskini almadan yapay veya sanal deneyim kazandığı bir yöntem olarak tanımlanmaktadır. Hemşirelik eğitiminde kullanılan simülasyon uygulamaları kapsamında; simülatörler (gerçek ya da simüle edilmiş hastalarla) ile rol oynama, bilgisayar temelli simülasyon, simülasyon software, video, DVD ya da sanal gerçeklik yaratılması, bilgisayar kontrollü simülatörler ve interaktif hasta simülatörleri yer almaktadır(2).Bradley; sağlık eğitimindesimülasyon yöntemini geniş bir bakış açısı ile ele almış ve sadece teknolojik bilgisayar imkanları olarak değil, aynı zamanda önemli derecede insan etkileşimini içeren bir eğitim yelpazesi olarak ifade etmiştir(3). Gaba'yagöre simülasyon ise; bir rehber öncülüğünde gerçek bir ortamı önceden deneyimlemeyi sağlayan bir tekniktir(4). Hersimülasyonda "fidelity" olarak bilinen "gerçek yaşama olan uygunluk" diğer bir deyişle "aslına uygunluk" özelliği bulunmalıdır. Gerçekte var olan tüm olası durumlar taklit edilebilmeli, katılımcının gerçeğe uygun şekilde yanıt verebileceği bir ortam sağlanmalıdır. Problemin ve içinde bulunulan durumun değişmesi ile simülatör katılımcının eylemlerine uygun hareket edebilmelidir. Simülasyon sisteminin özellikler ne kadar fazla ise katılımcılar öğrendiklerini gerçek durumlara o kadar aktarabilmektedir(5).

\section{Gereç ve Yöntem}

Çalışmada yarı yapılandırılmış altı soruyu içeren odak grup görüşme yöntemi kullanılmıştır. Örneklem grubuna lise eğitimini Sağllk Meslek Lisesi hemşirelik bölümünde tamamlamış SHMYO 2015-2016 Eğitim ve Öğretim y1lı İlk ve Acil Yardım Bölümü 1. ve 2. sınıf önlisans öğrencilerinden 30 gönüllü öğrenci seçilmiş ve her grupta 10 öğrenci olmak üzere toplam 3 odak grup görüşmesi yapılmıştır. Her grup bir gün içinde toplam 3 günde görüşme gerçekleştirerek toplanmıştır.Görüşülmeye aday öğrencilerle bireysel olarak yüz yüze birer ön görüşme yapılmıştır. Ön görüşmede, görüşmenin amac1, şekli ve tahmini tarihleri belirtilmiş, görüşmeye katılmak isteyip istemedikleri sorulmuştur. Görüş̧meler Sağlı Hizmetleri Meslek Yüksekokulu toplantı salonunda yapılmış ve ortalama 3 saat sürmüştür. Tüm görüşmeler yazılı olarak kaydedilmiştir.

Katılımcıların çoğunun görüşmelerdesamimicevaplar verdikleri gözlenmiştir. Buna karşın kimi katılımcının, kendisinin değerlendirildiğini düşünerek, biraz endişelendiği farkedilmiştir. Bu kişiler "Bana bir zararı olur mu?" vb. sorular yöneltmişlerdir. Katılımcıların endişeleri olağan karşılanarak ve çalışma amacının programı değerlendirmek olduğu, program değerlendirmenin en önemli ilkelerinden birinin katılımcıları incitmemek olduğu ve etik ilkeler açıklanarak giderilmeye çalışılmıştır.

Araştırmanın verilerinin toplanmasında öğrencilerin demografik özelliklerini içeren soru formu ve araştırmacılar tarafindan geliştirilen yarı yapılandırılmış görüşme formu kullanılmıştır. Görüşme formunda yer alan açık uçlu sorular aşağıda verilmiştir.

1. Çalışma alanına çıkmadan önce okul koşullarında klinik beceri ve yeterliliklerinizin geliştirilmesinde kullanılan öğretim yöntemleri ile ilgili ne düşünüyorsunuz?

2. Okuldaki eğitimde teorik aldığınız dersler sırasında verilen beceri ve yeterliliklerinizi geliştirme eğitiminin sizi klinik uygulamaya hazırlama durumuna ilişkin ne düşünüyorsunuz?

3. Klinik uygulamalarda mesleki becerilerinizin kullanılmasına yönelik karşılaştığınız güçlükler nelerdir?

4. Klinik uygulamaya çıkmadan önceden okul ortamında kendinizi daha yeterli hissedebilmek için nasıl bir eğitim almak istersiniz?

- Bu eğitimin içeriği ve yöntemleri neler olabilir?

5. Klinik uygulama becerilerinizin vaka çalışmaları ve maket (simulasyon) kullanarak yapılmasına yönelik ne düşünüyorsunuz?

6. Bu yöntemin avantaj ve dezavantajlarısizce neler olabilir?

Verilerin analizinde tüme varım yöntemi kullanılmıştır. İki kişinin yazılı kaydettiği materyallerde yer alan veriler karşılaştırılarak eksik ifadeler tamamlanmıştır. Görüşmelerden elde edilen veriler araştırmacı tarafindan oluşturulan temalarına göre alt gruplara ayrılmıştır. Öğrencilerin tanıtıcı özelliklerinin analizinde sayı ve yüzdelik kullanılmıştır.

\section{Bulgular}

Çalışmaya katılan öğrencilerin; yaş ortalamalarının 19,7 (min. 18, max. 23, SS \pm 1.8 ), \%97,6'sının kadın olduğu; \%11.7'sinin part-time olarak çalıştığı, \%29,6'sınının full-time olarak çalıştığı, \%70,7'sinin okulun 2. Döneminde, \%29,3'ünün okulun 4. Döneminde bulunduğu belirlenmiştir. Ayrıca öğrencilerin akademik ortalamalarının 4 üzerinden 3,05(min. 2,98, max 3.67, $\mathrm{SS} \pm 1.2$ ) olduğu, öğrencilerinhepsinin maket kullandığı 
(\%100) ve derste konu ile ilgili teorik bilgi aktarımı ile $(\% 43,9)$ simülasyonla ilgili bilgi sahibi oldukları saptanmıştır. Öğrencilerle yapılan görüşmeler sonunda üç ana tema belirlenmiştir;

1. Klinik öncesi beceri geliştirme alanlarının yeterliliği ile ilgili görüşler (soru 1,2,4),

2. Klinik uygulamada beceri kullanımıyla ilgili görüşler (soru 3),

3. Vaka çalışması ve simulasyon yönteminin kullanımıyla ilgili görüşler (soru 5,6).

Tema 1: Klinik Öncesi Beceri Geliştirme Alanlarının Yeterliliği İle İlgili Görüşler

Öğrencilerin geneli klinik öncesilaboratuarşartlarında verilen beceri geliştirme çalışmalarının kendilerine faydalı olduğunu belirtmişlerdir. Yaptıkları beceri geliştirme uygulamalarının, kullandıkları maketlerin uygulamaya yardımcı olan en son çıkan manyetik özellikli ve dışarıdan yönetilebilen, bilgisayara kaydedilebilen, sonradan hatalarını görebilme özellikleriyle nedeniyle mesleki becerigeliştirmede yeterince yararlı olduğunu vurgulamışlardır. Öğrenciler aldıkları teorik derslerle beraber vaka çalışmalarının ve konuyla ilgili videoların anlatılan bilgiyi pekiştirdiğini ve bundan memnun olduklarını ifade etmişlerdir. Aşağıda öğrencilerin konuya ilişkin ifadeleri yer almaktadır;

- 'Lisede kullandığımız maketlerde tepki yoktu, canının yandığını yada doğru-yanlış yaptığımızı bilmiyorduk. Ancak labaratuarımızda kullandığımız maketimiz uygulamaların doğru-yanlış olmasını kaydediyor, uyarı veriyor. Canı yandığında ses çıkarıyor. Kalp masajı yaparken doğru yere uygun bası ile uygulama yapmazsak maket bizi uyarıyor. Aspirasyon yaparken süreyi uzatırsak öğürme refleksi yapıyor, maket bize gerçek hastaya müdahale ediyormuşçasına tepki gösteriyor.

- 'Teorik derslerimizi vaka çalışmaları ve maketlerimizle desteklemek çok faydalı.Makette bilgilerim gelişiyor, makete zarar vermiyoruz.'

- $\quad$ 'Sesli uyaran gelmesi, kusması, boğulması, damaryolu açarken kan gelmesi, akciğer seslerini dinleyebilmek ve buna bağlı ön tanı oluşturmak, vital bulguların hepsini maket üzerinde ölçüp gerçek hastaymış gibi nabız, kalp atımı sayabilmek, ateşini ölçebilmek bizi geliştiriyor.'

Öğrenciler aldıkları teorik derslerle beraber vaka çalışmalarının ve konuyla ilgili videoların anlatılan bilgiyi pekiştirdiğini ve bundan memnun olduklarını ifade etmişlerdir. Aşağıda öğrencilerin konuya ilişkin ifadeleri yer almaktadır;

- 'Derslerin uygulama saatleri arttırılmalı ve daha fazla sayıda vaka tartışması olmalı.'

- 'Öğrenci aktif tutulmalı, öğrenciye daha fazla söz verilmeli.'

Tema 2: Klinik Uygulamada Beceri Kullanımıyla İlgili Görüşler

Öğrencilerin büyük kısmı alanda ya da hastanede kendilerini okul süresince beceri labaratuarlarında çok fazla pratik yaptıkları içinkendilerine güvenlerinin yüksek hissettiklerini ifade etmişlerdir. Okulda öğrendikleri bilgi ile klinik alandaki uygulamaların bazen uyuşmadığını, alanda kurallara uymaya özen göstermediklerini belirtmişlerdir. Aşağıda öğrencilerin konu ile ilgili ifadesi verilmiştir;

- 'Tam beceri kazandığımızdan çoğu göreve katılıyoruz. Ancak biz hastanın tansiyon ölçerkensteteskopun diyaframını manşonun içine koymuyoruz, uzuvdaki nabız aldığımız arterin üzerine koyarak ölçüm yapıyoruz.'

- 'Alanda çalışanlar steteskop kullanmıyorlar yadasteteskopu manşonun içine koyarak ölçüm yapıyorlar.'

Tema 3: Vaka Çalışması Ve Simulasyon Yönteminin Kullanımıyla İlgili Görüşler

Öğrencilere mesleki beceri eğitiminin vaka çalışması ve maket (simulasyon) kullanılarak yapılmasına yönelik düşünceleri sorulduğunda hepsi bu eğitimin kendileri için yararlı olduğunu ifade etmişlerdir. Aşağıda öğrencilerin konu ile ilgili ifadeleri verilmiştir;

- 'Klinik öncesisimülatördeuygulama yapmak kendimize güvenimizi arttırıyor.'

- 'Vaka çalışmaları bizi çalışma hayatına ve gerçek hastalara hazırlıyor.'

- 'Uygulama dersi saatlerini arttırmak yararlı olabilir. Simülasyon maketleri çeşitlendirilebilir.'

\section{Tartıșma}

Simülasyon kullanımı, öğrencilerin konforlu ve destekleyici bir ortamda yeni edindikleri beceriyi güven içinde yapmalarına destek vermesi açısından önemlidir (6).Ögrenme ortamlarında gerçek hayatın yansıtılması gereğini ön plana çıkaran durumlu öğrenme kuramında da belirtiği üzere öğrenme öğretme süreçlerinde, birebir yetiştirme ve simülasyongibi çoklu uygulama bileşenlerinin kullanılması, öğrencilerin gerçek dünya bağlamında deneyimler kazanmasını sağlar(7).

Öğrenciler açısından yaptıkları pratik uygulamanın fazla olması anksiyetelerinin azalmasını sağlayarak özgüvenlerinin geliştirmekte ve yaptıkları işin kalitesini artırmaktadır(8). Çalışmamızda, öğrencilerin klinik öncesi hazırlıkları açısından simülasyon maketinde kullanmanın faydalı olduğu ancak uygulama saatlerinin arttırılması gerektiği; klinik ortamda kendilerine güvenlerinin olduğunu, hastane ortamında uygulananla teorikte anlatılanlarda az da olsa farklılık olduğu belirlenmiştir.Bu doğrultudasimülasyon eğitiminin, öğrencileri alana 
hazırlamada etkin olacağı, öğrencinin klinik düşünme, karar alma ve uygulama becerisini pekiştirerek, özgüvenini artıracağı düşünülmektedir.Demir'in çalışmasında öğrencilerin klinik uygulamada beklentilerinin karşılanmadığı(9), teorikte anlatılanlarla klinikte uygulananlar arasındaki farklılıklar olduğu vurgulanmaktadır(8). Ricketts yaptığı çalışmada mesleki beceri laboratuvarında yapılan simülasyonlu eğitimin öğrencileri gerçek klinik ortama uyumunu sağladığını ve klinik becerilerinin arttığını saptamıştır(10).Benzer şekilde Goldenberg ve diğerleri klinik öncesi uygulanan senaryo/bilgisayarlı simülasyon eğitiminin kritik durumlarda karar verme ile kognitif, psikomotor, iletişim, tartışma ve öğretim becerilerinde artmaya neden olduğunu saptamıştır.(11). Bizim çalışmamızda da öğrenciler labaratuar uygulamalı derslerde mesleki becerilerinin arttığını ve pratiklik kazandıklarını ifade etmişlerdir. Roh ve ark. yaptıkları çalışmada hemşirelik öğrencileri üzerinde simülasyon temelli eğitimin öğrencilerin resusitasyon işlemi sırasında öz yeterliliklerini ve memnuniyetlerini artırdığını belirtmiştir(12). Öğrencilerimiz simülasyon maketinde resüsitasyon çalışması yaparken kendilerini daha yetkin gördüklerini ve gerçek hastaya müdahale ederken yapacakları doğru adımları önceden maket üzerinde pratik yapmayı ve alışkanlık kazanmayı arttırdığını belirtmişlerdir.Yuan ve arkadaşları simülasyonda kazanılan deneyiminin gerçek hasta/duruma aktarılabilmesinin incelenmesine gereksinim olduğunu belirtmiş̧tir(13). Resüsitasyon çalışmalarında uygulama ve vaka çalışmalarının arttırılmasının faydalı olabileceği düşünülmektedir. Ayrıca uygulamaların maketlerin üzerindeki etkilerini görerek kendilerini geliştirmede çok önemli olduğuna ulaşılmıştır.

\section{Sonuç}

Sağlık eğitimi bilişsel, duyuşsal ve psikomotor öğrenme ortamlarını kapsayan bir sistem gerektirdiğinden; mezun olan öğrencilerin bu özellikler açısından tam donanımlı olması sağlanmalıdır. Öğrencilerin, hastaya uygulama yapmadan laboratuar ortamında klinik yeterliliklerinin artırılması hedefine ulaşmada önemli bir eğitim yöntemidir. Sahaya çıkmadan önce gerçeğe uygun vakalarla birleşmiş ortamı yansıtan bir laboratuarda mesleki becerilerini geliştirebilmektedirler. Literatüre benzer şekilde çalışmamıza katılan öğrenciler hastaya uygulamayı yapmadan önce alınan simülasyon eğitiminin öz güvenlerini artıracağını düşünmektedirler. $\mathrm{Bu}$ doğrultuda simülasyon eğitiminin, öğrencinin kliniğe hazırlamada etkili olacağı, öğrencinin klinik karar verme ve uygulama becerisini geliştirerek, özgüvenini artıracağı düşünülmektedir. Öğrencilere katkı sağlaması nedeniyle, simülasyon uygulamasının eğitim yöntemi olarak kullanılması ve yaygınlaştııılması önerilmektedir. Ayrıca labaratuarda yapılan uygulama saatlerinin ve vaka çalışmalarının arttırılması ile daha etkin eğitim verilebileceği önerilmektedir. Sağlık çalışanı eğitimi yapılan okullarda mesleki beceriye dayanan derslerde mutlaka simülasyonuygulamalarının sık sık kullanılması önerilebilir.

\section{Alana Katk1}

Çalışma sonuçları öğrencilerin mesleki becerilerinipozitif açıdan etkileyen özellikleri oluşturması nedeniyle bu konuyla ilişkili az sayıda bilgi yer alanliteratüre katkı sağlayacak; ardındanklinik beceri ve yeterliliğigeliştirmeye yönelik yapılacak olan çalışmalara ışık tutacaktır.

\section{VII. Çıkar Çatışması}

Bu makale herhangi bir nakdî/ayni yardım alınmadan oluşturulmuştur. Herhangi bir kişi ve/veya kurum ile ilgili çıkar çatışması bulunmamaktadır.

\section{Kaynaklar}

[1]. Edeer Durmaz A, Sarıkaya A. (2015) Hemşirelik Eğitiminde Simülasyon Kullanımıve Simülasyon Tipleri. Hemşirelikte Eğitim Ve Araştırma Dergisi, 12 (2): 121-125.

[2]. Alinier, G. (2007). A typology of educationallyfocusedmedicalsimulationtools. Medicalteacher, 29(8), e243-e250.

[3]. Bradley, P. (2006). Thehistory of simulation in medicaleducationandpossiblefuturedirections. Medicaleducation, 40(3), 254-262.

[4]. Gaba, D. M. (2007). Thefuturevision of simulation in healthcare. Simulation in Healthcare, 2(2), 126-135.

[5]. Hovancsek, M. T. (2007). Using simulation in nursingeducation.Jeffries, P. R. (Ed.). Simulation in NursingEducation. NationalLeagueforNursing, New York, 2-6.

[6]. Bremner, M. N.,Aduddell, K., Bennett, D. N., \&VanGeest, J. B. (2006). Theuse of humanpatientsimulators: Best practiceswithnovicenursingstudents. NurseEducator, 31(4), 170-174.

[7]. K1lı̧, E. (2004). Durumlu öğrenme kuramının eğitimdeki yeri ve önemi. Gazi Üniversitesi Gazi Eğitim Fakültesi Dergisi, 24(3).

[8]. Karaöz, S. (1997). Hemşirelik Esasları dersi alan öğrencilerin klinik uygulamaya ilişkin değerlendirmeleri. Cumhuriyet Üniv. Hemşirelik Yüksekokulu Dergisi, 1(1), 23-30.

[9]. Demir Y, Gökdoğan F. (2002). Öğrencilerin "psikiyatri hemşireliği” dersini değerlendirmesi. Düzce Tıp Fakültesi Dergisi, 4(3), 10-15.

[10]. Ricketts, B. (2011). The role of simulationforlearningwithinpre-registrationnursingeducation-a literaturereview. NurseEducationToday, 31(7), 650-654. 
[11]. DollyGoldenbergPhD, R. N.,\&CarrolliwasiwEdD, R. N. (2005). Theeffect of classroomsimulation on nursingstudents' self-efficacyrelatedtohealthteaching. Journal of NursingEducation, 44(7), 310.

[12]. Roh, Y. S., Lee, W. S., Chung, H. S., \& Park, Y. M. (2013). Theeffects of simulation-basedresuscitationtraining on nurses' self-efficacyandsatisfaction. NurseEducationToday, 33(2), 123-128.

[13]. Yuan, H. B., Williams, B. A., \&Fang, J. B. (2012). Thecontribution of high- fidelitysimulationtonursingstudents' confidenceandcompetence: a systematicreview. International NursingReview, 59(1), 26-33. 